Research Paper

\title{
Impact of Weight Loss at Presentation on Survival in Epidermal Growth Factor Receptor Tyrosine Kinase Inhibitors (EGFR-TKI) Sensitive Mutant Advanced Non-small Cell Lung Cancer (NSCLC) Treated with First-line EGFR-TKI
}

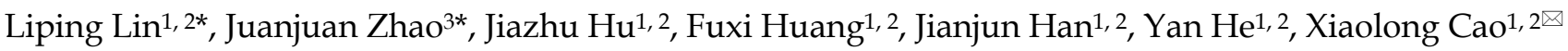 \\ 1. Department of Oncology, Panyu Central Hospital, Guangzhou, China, \\ 2. Cancer Institute of Panyu, Guangzhou, China \\ 3. School of Nursing, Sun Yat-sen University, Guangzhou, China \\ * These authors contribute equally to this work.
}

$\square$ Corresponding author: Xiaolong Cao, E-mail: pyzh1616@sina.com. Address: Department of Oncology, Panyu Central Hospital, No.8 Fuyu Road East, Panyu, Guangzhou, Guangdong Province, People's Republic of China. Fax: +86(020)34858309; Tel: +86(020)34859212

(c) Ivyspring International Publisher. This is an open access article distributed under the terms of the Creative Commons Attribution (CC BY-NC) license (https://creativecommons.org/licenses/by-nc/4.0/). See http://ivyspring.com/terms for full terms and conditions.

Received: 2017.08.15; Accepted: 2017.11.25; Published: 2018.01.01

\begin{abstract}
Purpose The aim of this study is to evaluate the impact of weight loss at presentation on treatment outcomes of first-line EGFR-tyrosine kinase inhibitors (EGFR-TKI) in EGFR-TKI sensitive mutant NSCLC patients.

Methods We retrospectively analyzed the clinical outcomes of 75 consecutive advanced NSCLC patients with EGFR-TKI sensitive mutations (exon 19 deletion or exon 21 L858R) received first-line gefitinib or erlotinib therapy according to weight loss status at presentation in our single center.

Results Of 75 EGFR-TKI sensitive mutant NSCLC patients, 49 (65.3\%) patients had no weight loss and $26(34.7 \%)$ had weight loss at presentation, the objective response rate (ORR) to EGFR-TKI treatment were similar between the two groups $(79.6 \%$ vs. $76.9 \%, p=0.533)$. Patients without weight loss at presentation had significantly longer median progression free survival (PFS) (12.4 months vs. 7.6 months; hazard ratio [HR] 0.356, 95\% confidence interval $[\mathrm{Cl}] 0.212-0.596, p<$ $0.001)$ and overall survival (OS) (28.5 months vs. 20.7 months; HR $0.408,95 \% \mathrm{Cl} 0.215-0.776, p=$ 0.006 ) than those with weight loss at presentation; moreover, the stratified analysis by EGFR-TKI sensitive mutation types also found similar trend between these two groups except for OS in EGFR exon 21 L858R mutation patients. Multivariate analysis identified weight loss at presentation and EGFR-TKI sensitive mutation types were independent predictive factors for PFS and OS.

Conclusions Weight loss at presentation had a detrimental impact on PFS and OS in EGFR-TKI sensitive mutant advanced NSCLC patients treated with first-line EGFR-TKI. It should be considered as an important factor in the treatment decision or designing of EGFR-TKI clinical trials.
\end{abstract}

Key words: Weight loss, EGFR mutation, EGFR-tyrosine kinase inhibitors, non-small cell lung cancer

\section{Introduction}

Lung cancer is still the leading cause of cancer-related death worldwide [1]. Approximately $80 \%-85 \%$ of cases are NSCLC, whereas around
$40 \%-60 \%$ of patients are diagnosed with advanced disease [2]. In the era of cytotoxic chemotherapy, the outcomes of these patients are very poor, with the 
median OS was no more than 12 months [3]. Fortunately, with the introduction of EGFR-TKI and the discovery of EGFR-TKI sensitive mutations (EGFR exon 19 deletion or exon 21 L858R mutations), the OS of advanced EGFR-TKI sensitive mutant NSCLC patients have been improved greatly, and EGFR-TKI has replace cytotoxic chemotherapy as standard first-line treatment for these patients [4-6]. However, it isn't all EGFR-TKI sensitive mutant NSCLC patients can have prolonged survival from EGFR-TKI treatment. Although the median PFS of EGFR-TKI treatment was about 9-10 months, it had a very wide range from 2 to 73 months, and there was also a similar result on OS with various ranges $[7,8]$. These findings suggest the clinical outcomes among EGFR-TKI sensitive mutant NSCLC patients are heterogeneous, yet the clinical factors affecting these are unclearly.

Weight loss at presentation is a common clinical factor in advanced NSCLC. It happened in $54 \%$ of NSCLC patients and is essentially because of an imbalance between energy intake and expenditure, which may be caused by tumor related factors, such as anorexia, nausea and vomiting, diarrhea, pain and so on [9]. There has convincing evidences that weight loss is an independent poorer prognostic factor in NSCLC [10, 11]. Besides the effect on survival, it is also an adverse factor on response to chemotherapy and quality of life [12]. Based on these results, we hypothesized that weight loss at presentation may had a detrimental impact on survival in EGFR activating mutant advanced NSCLC patients treated with first-line EGFR-TKI, and the patients with weight loss at presentation would exhibit poorer outcomes than those without weight loss.

Therefore, to investigate the impact of weight loss at presentation on survival of first-line EGFR-TKI therapy in EGFR-TKI sensitive mutant NSCLC patients, we retrospectively analyzed the clinical outcomes to first-line EGFR-TKI treatment in advanced NSCLC patients with EGFR-TKI sensitive mutations according to patients' weight loss status at presentation in our single center.

\section{Material and Methods}

\section{Patients}

This retrospective study was approved by the institutional ethics committee of Guangzhou Panyu Central Hospital. A cohort of all consecutive advanced NSCLC patients with EGFR-TKI sensitive mutations treated with first-line EGFR-TKI from January 2011 to April 2015 at department of oncology of Guangzhou Panyu Central Hospital were enrolled in. The inclusion criteria as follows: histologically or cytologically confirmed NSCLC; stage IIIB or IV according to $7^{\text {th }}$ edition tumor/node/metastasis (TNM) system; harbor EGFR exon 19 deletion or exon 21 L858R mutations; treatment with first-line gefitinib ( $250 \mathrm{mg}$ / day orally) or erlotinib (150 mg / day orally); has at least one measurable target lesions; PS $\leq 3$.

Exclusion criteria included: harbor uncommon EGFR mutations; presence of another cancer; accompanied by chemotherapy; received irradiation to target lesions before progression; had a cessation for taking medicine more than two weeks during treatment. We divided the included patients into two groups according to with or without weight loss at presentation.

\section{Weight measurement and definition of weight loss}

Patients' weight were measured at the time of diagnosis, and weight loss was defined as a weight loss more than $5 \%$ in 3 months before diagnosis, which was in accordance with the international consensus on definition and classification of cancer cachexia [13].

\section{EGFR mutation analysis}

EGFR mutations were detected using real-time polymerase chain reaction (PCR). Our previous research had described the details of the methods [14].

\section{Clinical efficacy assessment}

Organ functions in baseline were evaluated before EGFR-TKI treatment for every patient. All patients were eligible for receiving first-line gefitinib or erlotinib therapy, which were continued to disease progression, unacceptable toxicities or deaths. Physical examination, chest radiography, computed tomography (CT) scan or /and magnetic resonance image (MRI) were used to evaluate target and non-target lesions for all patients. The first response evaluation was done after 1 month of treatment and then every 2 months in follow-up. Tumor responses were classified according to the Response Evaluation Criteria in Solid Tumors (version 1.1) [15].

\section{Statistical analysis}

Statistical analyses for comparisons between groups were performed using the chi-squared test or Fisher's exact test for qualitative variables, and Student's t-test or the Mann-Whitney test for continuous variables. Reverse Kaplan-Meier estimate was used to calculate median follow-up. PFS (defined as the date of EGFR-TKI treatment to disease progression or death from any cause) and OS (defined as the date of EGFR-TKI treatment to the date of death from any cause or the last visit before April 30, 2017, censored at the date of last follow up) on entire 
population and stratified by EGFR-TKI sensitive mutation types (exon 19 deletion or exon 21 L858R mutation) were analyzed using Cox proportional hazards regression model and presented as Kaplan-Meier estimates with hazard ratio (HR) and 95\% confidence interval (CI). A Cox multivariate regression analysis was done on PFS and OS, and covariates included brain metastasis, age, sex, PS, smoking status, with or without weight loss at presentation, EGFR-TKI sensitive mutation types (19 deletion vs. 21 L858R), types of EGFR-TKI (erlotinib or gefitinib), and second-line treatments (no vs. yes). Statistical significance was set at 5\%. All tests were two-sided and analyses were carried out with SPSS software, version 17.0 (SPSS Inc., Chicago, IL, USA).

\section{Results}

\section{Patient Characteristics}

A total of 75 advanced NSCLC patients with EGFR exon 19 deletion or exon 21 L858R mutation treated with first-line gefitinib or erlotinib were identified. Among 75 patients, the median age was 59 (range: 23-90) years, 52 (69.3\%) were never-smokers, $41(54.7 \%)$ were women and 66 (88.0\%) were adenocarcinoma. The majority of the patients were PS 0-1 (63 patients, $84 \%$ ) and stage IV disease (73 patients, 97.3\%). Furthermore, $42(56.0 \%)$ and 33 (44.0\%) patients harbored EGFR exon 19 deletion and exon 21 L858R mutation, respectively. The patient characteristics stratified by weight loss status at presentation are detailed in table 1. Patients' PS were worsen in with weight loss group than without weight loss group $(p=0.002)$.

\section{Response to EGFR-TKI}

The tumor responses to EGFR-TKI treatment are shown in table 2 . One (1.3\%) and $58(77.3 \%)$ of 75 patients showed complete response (CR) and partial response (PR), respectively. Of the 49 patients without weight loss at presentation, 39 (79.6\%) showed PR. On the other hand, CR and PR were observed in 1 (3.8\%) and $19(73.1 \%)$ of 26 patients with weight loss. Thus, the response rate to EGFR-TKI treatment were similar between two groups $(p=0.533)$.

\section{Effect of weight loss at presentation on PFS and OS}

The median follow-up time was 20.8 (range: 6.6-63.6) months. The median PFS for whole population was 10.3 months (95\% CI: 9.0-11.6). Patients without weight loss at presentation had a significantly longer PFS than those with weight loss at presentation (12.4 [95\% CI 10.2-14.6] months vs. 7.6 [95\% CI 5.7-9.5] months; HR: 0.356, 95\% CI $0.212-0.596, p<0.001$ ) (Figure 1a). The stratified analysis by EGFR-TKI sensitive mutation types also found patients without weight loss had significantly longer PFS than those with weight loss, regardless of EGFR exon 19 deletion (15.3 [95\% CI 13.2-17.4] months vs. 7.9 [95\% CI 6.7-9.0] months; HR: 0.273, 95\% CI 0.133-0.557, $p<0.001$ ) (Figure $1 b$ ) or EGFR exon 21 L858R mutation (9.8 [95\% CI 8.1-11.5] months vs. 4.0 [95\% CI 3.5-4.5] months; HR: $0.402,95 \%$ CI $0.185-0.874, p=0.021$ ) (Figure 1c). In multivariate analysis, with or without weight loss at presentation $(p<0.001)$ and EGFR-TKI sensitive mutation types $(p$ $<0.001)$ were identified as independent predictors of PFS ( table 3).

Table 1. Patients clinical characteristics according to weight loss status

\begin{tabular}{|c|c|c|c|}
\hline Clinical characteristics & $\begin{array}{l}\text { Without weight loss } \\
(\mathrm{n}=49)(\%)\end{array}$ & $\begin{array}{l}\text { With weight loss } \\
(\mathrm{n}=26)(\%)\end{array}$ & P-value \\
\hline Median age(range), years & $59(37-83)$ & $57(23-90)$ & 0.570 \\
\hline \multicolumn{4}{|l|}{ Age, years } \\
\hline$<65$ & $35(71.4)$ & $18(69.2)$ & \multirow[t]{2}{*}{0.842} \\
\hline$\geq 65$ & $14(28.6)$ & $8(30.8)$ & \\
\hline \multicolumn{4}{|l|}{ Sex } \\
\hline Male & $21(42.9)$ & $13(50.0)$ & \multirow[t]{2}{*}{0.554} \\
\hline Female & $28(57.1)$ & $13(50.0)$ & \\
\hline \multicolumn{4}{|l|}{ Smoking status } \\
\hline No & $37(75.5)$ & $15(57.7)$ & \multirow[t]{2}{*}{0.111} \\
\hline Yes & $12(24.5)$ & $11(42.3)$ & \\
\hline \multicolumn{4}{|l|}{ Stage } \\
\hline IIIB & $2(4.1)$ & $0(0.0)$ & \multirow[t]{2}{*}{0.296} \\
\hline IV & 47 (95.9) & $26(100.0)$ & \\
\hline \multicolumn{4}{|l|}{ Performance status } \\
\hline $0-1$ & $46(93.9)$ & $17(65.4)$ & \multirow[t]{3}{*}{0.002} \\
\hline 2 & $3(6.1)$ & $8(30.8)$ & \\
\hline 3 & $0(0.0)$ & $1(3.8)$ & \\
\hline \multicolumn{4}{|l|}{ Histopathological types } \\
\hline Adenocarcinoma & $43(87.8)$ & $23(88.5)$ & \multirow[t]{4}{*}{0.528} \\
\hline Squamous cell carcinoma & $1(2.9)$ & $2(7.7)$ & \\
\hline Adenosquamous carcinoma & $1(2.0)$ & $0(0.0)$ & \\
\hline Not other special, NOS & $4(8.2)$ & $1(3.8)$ & \\
\hline \multicolumn{4}{|l|}{$\begin{array}{l}\text { EGFR-TKI sensitive mutation } \\
\text { types }\end{array}$} \\
\hline Exon 19 deletion & $26(53.1)$ & $16(61.5)$ & \multirow[t]{2}{*}{0.482} \\
\hline Exon 21 L858R & $23(46.9)$ & $10(38.5)$ & \\
\hline \multicolumn{4}{|l|}{ Types of EGFR-TKI } \\
\hline Gefitinib & $40(81.6)$ & $22(84.6)$ & \multirow[t]{2}{*}{0.745} \\
\hline Erlotinib & $9(18.4)$ & $4(15.4)$ & \\
\hline \multicolumn{4}{|l|}{ Brain metastasis } \\
\hline Yes & $13(26.5)$ & $6(23.1)$ & \multirow[t]{2}{*}{0.743} \\
\hline No & $36(73.5)$ & $20(76.9)$ & \\
\hline
\end{tabular}

Table 2. Response according to weight loss status

\begin{tabular}{llll}
\hline Response & $\begin{array}{l}\text { Overall patients } \\
(\mathrm{n}=75)(\%)\end{array}$ & $\begin{array}{l}\text { Without weight loss } \\
(\mathrm{n}=49)(\%)\end{array}$ & $\begin{array}{l}\text { With weight loss } \\
(\mathrm{n}=26)(\%)\end{array}$ \\
\hline $\begin{array}{l}\text { Complete } \\
\text { response }\end{array}$ & $1(1.3 \%)$ & $0(0.0 \%)$ & $1(3.8 \%)$ \\
$\begin{array}{l}\text { Partial } \\
\text { response }\end{array}$ & $58(77.3)$ & $39(79.6 \%)$ & $19(73.1 \%)$ \\
$\begin{array}{l}\text { Stable disease } \\
\text { Progression } \\
\text { disease }\end{array}$ & $14(18.7 \%)$ & $9(18.4 \%)$ & $5(19.2 \%)$ \\
\hline
\end{tabular}



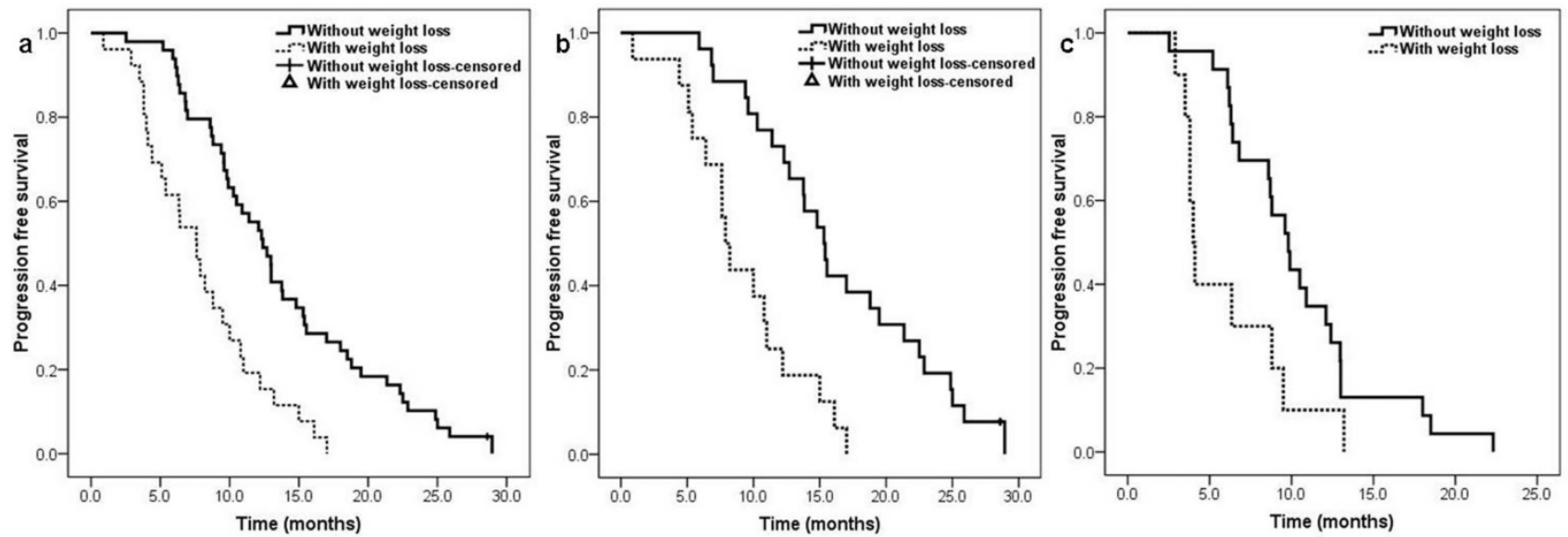

Figure 1. Kaplan-Meier curve for progression free survival according to patients' weight loss status at presentation: a. overall population, b. EGFR exon 19 deletion population, c. EGFR exon 21 L858R mutation population.

Table 3. Predictors of PFS analyzed by the Cox regression model

\begin{tabular}{|c|c|c|c|c|}
\hline \multirow[t]{2}{*}{ Variable } & \multicolumn{2}{|c|}{ Univariate analysis } & \multicolumn{2}{|l|}{$\begin{array}{l}\text { Multivariate } \\
\text { analysis }\end{array}$} \\
\hline & $\mathrm{HR}(95 \% \mathrm{CI})$ & $\begin{array}{l}\text { P- } \\
\text { value }\end{array}$ & $\mathrm{HR}(95 \% \mathrm{CI})$ & $\begin{array}{l}\text { P- } \\
\text { value }\end{array}$ \\
\hline $\begin{array}{l}\text { Weight loss status (without weight loss } \\
\text { vs. with weight loss) }\end{array}$ & $\begin{array}{l}0.356 \\
(0.212-0.596)\end{array}$ & $\begin{array}{l}< \\
0.001\end{array}$ & $\begin{array}{l}0.315 \\
(0.180-0.553)\end{array}$ & $\begin{array}{l}< \\
0.001\end{array}$ \\
\hline Age ( $<65$ vs. $\geq 65$ years $)$ & $\begin{array}{l}0.745 \\
(0.447-1.241)\end{array}$ & 0.258 & $\begin{array}{l}1.406 \\
(0.810-2.441)\end{array}$ & 0.226 \\
\hline Sex (male vs. female) & $\begin{array}{l}1.642 \\
(1.014-2.563)\end{array}$ & 0.044 & $\begin{array}{l}0.689 \\
(0.316-1.505)\end{array}$ & 0.350 \\
\hline Smoking status (no vs. yes) & $\begin{array}{l}0.495 \\
(0.299-0.820)\end{array}$ & 0.006 & $\begin{array}{l}0.738 \\
(0.323-1.686)\end{array}$ & 0.471 \\
\hline Stage (IIIB vs. IV) & $\begin{array}{l}1.010 \\
(0.245-4.170)\end{array}$ & 0.989 & Excluded & \\
\hline PS (2-3 vs. $0-1)$ & $\begin{array}{l}1.440 \\
(0.768-2.699)\end{array}$ & 0.256 & $\begin{array}{l}1.071 \\
(0.520-2.204)\end{array}$ & 0.852 \\
\hline $\begin{array}{l}\text { Histopathological types } \\
\text { (non-adenocarcinoma vs. } \\
\text { adenocarcinoma) }\end{array}$ & $\begin{array}{l}0.966 \\
(0.479-1.948)\end{array}$ & 0.924 & Excluded & \\
\hline $\begin{array}{l}\text { EGFR-TKI sensitive mutation } \\
\text { types (19 deletion vs. } 21 \text { L858R) }\end{array}$ & $\begin{array}{l}0.430 \\
(0.263-0.703)\end{array}$ & 0.001 & $\begin{array}{l}0.358 \\
(0.210-0.611)\end{array}$ & $\begin{array}{l}< \\
0.001\end{array}$ \\
\hline $\begin{array}{l}\text { Types of EGFR-TKI (erlotinib vs. } \\
\text { gefitinib) }\end{array}$ & $\begin{array}{l}0.875 \\
(0.478-1.603)\end{array}$ & 0.666 & $\begin{array}{l}0.835 \\
(0.441-1.582)\end{array}$ & 0.581 \\
\hline Brain metastasis (no vs. yes) & $\begin{array}{l}0.834 \\
(0.489-1.424)\end{array}$ & 0.507 & $\begin{array}{l}0.768 \\
(0.424-1.391)\end{array}$ & 0.383 \\
\hline
\end{tabular}

The median OS on entire population was 25.0 months (95\% CI: 22.1-27.8). The median OS of patients without weight loss at presentation was also significantly longer than those with weight loss (28.5 [95\% CI 23.5-33.5] months vs. 20.7 [95\% CI 17.5-23.9] months; HR: 0.408, 95\% CI 0.215-0.776, $p=0.006$ ) (Figure 2a). In EGFR exon 19 deletion patients, patients without weight loss had significantly longer OS than patients with weight loss (36.8 [95\% CI 26.9-46.8] months vs. 22.7 [95\% CI 18.5-26.9] months; HR: $0.263,95 \%$ CI 0.099-0.695, $p=0.007$ ) (Figure 2b), however, there was no significant difference in OS between patients without weight loss and patients with weight loss for EGFR exon 21 L858R mutation patients (20.2 [95\% CI 17.6-22.8] months vs. 15.8 [95\% CI 12.8-18.8] months; HR: 0.511, 95\% CI 0.215-1.214, $p$ $=0.128$ ) (Figure 2c). Multivariate analysis identified with or without weight loss at presentation $(p=0.011)$ and EGFR-TKI sensitive mutation types $(p=0.009)$ as independent predictors of OS (table 4).

Table 4. Predictors of OS analyzed by the Cox regression model

\begin{tabular}{|c|c|c|c|c|}
\hline \multirow[t]{2}{*}{ Variable } & \multicolumn{2}{|c|}{ Univariate analysis } & \multicolumn{2}{|l|}{$\begin{array}{l}\text { Multivariate } \\
\text { analysis }\end{array}$} \\
\hline & HR $(95 \%$ CI) & $\begin{array}{l}\mathrm{P}- \\
\text { value }\end{array}$ & HR $(95 \% \mathrm{CI})$ & $\begin{array}{l}\mathrm{P} \text { - } \\
\text { value }\end{array}$ \\
\hline $\begin{array}{l}\text { Weight loss status (without weight loss } \\
\text { vs. with weight loss) }\end{array}$ & $\begin{array}{l}0.408 \\
(0.215-0.776)\end{array}$ & 0.006 & $\begin{array}{l}0.384 \\
(0.183-0.805)\end{array}$ & 0.011 \\
\hline Age $(<65$ vs. $\geq 65$ years $)$ & $\begin{array}{l}0.528 \\
(0.280-0.994)\end{array}$ & 0.048 & $\begin{array}{l}1.975 \\
(0.994-3.924)\end{array}$ & 0.052 \\
\hline Sex (male vs. female) & $\begin{array}{l}1.451 \\
(0.802-2.625)\end{array}$ & 0.219 & $\begin{array}{l}1.190 \\
(0.461-3.069)\end{array}$ & 0.718 \\
\hline Smoking status (no vs. yes) & $\begin{array}{l}0.398 \\
(0.206-0.768)\end{array}$ & 0.006 & $\begin{array}{l}0.847 \\
(0.259-2.771)\end{array}$ & 0.259 \\
\hline Stage (IIIB vs. IV) & $\begin{array}{l}1.010 \\
(0.245-4.170)\end{array}$ & 0.989 & Excluded & \\
\hline PS (2-3 vs. $0-1)$ & $\begin{array}{l}1.205 \\
(0.507-2.867)\end{array}$ & 0.673 & $\begin{array}{l}0.991 \\
(0.359-2.733)\end{array}$ & 0.986 \\
\hline $\begin{array}{l}\text { Histopathological types } \\
\text { (non-adenocarcinoma vs. } \\
\text { adenocarcinoma) }\end{array}$ & $\begin{array}{l}1.129 \\
(0.501-2.543)\end{array}$ & 0.769 & Excluded & \\
\hline $\begin{array}{l}\text { EGFR-TKI sensitive mutation types (19 } \\
\text { deletion vs. } 21 \text { L858R) }\end{array}$ & $\begin{array}{l}0.393 \\
(0.217-0.713)\end{array}$ & 0.002 & $\begin{array}{l}0.381 \\
(0.186-0.784)\end{array}$ & 0.009 \\
\hline $\begin{array}{l}\text { Types of EGFR-TKI (erlotinib vs. } \\
\text { gefitinib) }\end{array}$ & $\begin{array}{l}0.345 \\
(0.122-0.978)\end{array}$ & 0.045 & $\begin{array}{l}0.336 \\
(0.112-1.008)\end{array}$ & 0.052 \\
\hline Brain metastasis (no vs. yes) & $\begin{array}{l}0.984 \\
(0.485-1.998)\end{array}$ & 0.965 & Excluded & \\
\hline Second-line treatment (no vs. yes) & $\begin{array}{l}0.684 \\
(0.367-1.276)\end{array}$ & 0.233 & $\begin{array}{l}0.661 \\
(0.334-1.331)\end{array}$ & 0.236 \\
\hline
\end{tabular}

\section{Second-line treatment}

Overall, $50(66.7 \%)$ of 75 patients received second-line treatment, and it was $32(65.3 \%)$ of 49 patients in without weight loss group and 18 (69.2\%) of 26 patients in with weight loss group, the proportion of patients received second-line treatment was similar between the two group $(p=0.731)$. The most common regimens in second-line therapy were in two groups gemcitabine combined with platinum (Table 5). 


\section{Toxicities}

The most common drug-related toxicities were listed in table 6. In two groups, rash was the most frequent drug-related toxicities, there were $12.2 \%$ and $15.4 \%$ of patients experiencing grade 3-4 rash in without weight loss group and with weight loss group respectively. Moreover, diarrhea is another most common adverse event. However, all of drug-related toxicities were well tolerated, and the incidences of these toxicities were similar between two groups.

\section{Discussion}

To our best knowledge, at present, there are no published data on impact of weight loss at presentation on PFS and OS in EGFR-TKI sensitive mutant advanced NSCLC patients treated with first-line EGFR-TKI, and it is the first study to examine this. The present results showed that EGFR-TKI sensitive mutant advanced NSCLC patients without weight loss at presentation had significantly longer PFS and OS than those with weight loss at presentation in first-line EGFR-TKI treatment, the stratified analysis by EGFR-TKI sensitive mutation types also found similar trend between these two groups except for OS in EGFR exon 21 L858R mutation patients which may be due to the small sample size. In multivariate analysis, weight loss at presentation and EGFR-TKI sensitive mutation types were confirmed as independent adverse predictive factors for both PFS and OS. These findings suggest the necessity for nutritional intervention in these patients. Moreover, although one study found that toxicities were more common in advanced lung cancer patients with weight loss when receiving platinum-based chemotherapy [16], we didn't find any significant difference in adverse events between two groups in this analysis, which may be because the toxicities of EGFR-TKI were slight and all population could be well tolerated.

One study compared the characteristics of patients who experience early progression with patients whose disease was controlled after receiving erlotinib or gefitinib for at least 7 days, and the univariate analysis results showed that weight loss $\geq 10 \%$ was one of clinical factors associated with early progression [17]. This was the only study reported weight loss was associated with poorer outcome in patients treated with EGFR-TKI. Nevertheless, tumors of EGFR mutation status were unknown and patients received different lines of EGFR-TKI treatment in that study, in addition, weight loss was excluded from the multivariate analysis. In contrast to that, all patients had EGFR-TKI sensitive mutations and received first-line EGFR-TKI treatment in our study, the negative effect of weight loss at presentation on survival was confirmed in both univariate and multivariate analyzes. Therefore, there are less mixed factors in the present study and the results are more convincing than those of the aforementioned study.

Interestingly, several studies investigated the impact of other weight-related clinical characteristics such as body mass index (BMI), body surface area (BSA), and body weight (BW) at diagnosis on survival for EGFR-TKI therapy in EGFR mutant NSCLC patients [18-21]. However, the conclusions of these studies about the effects of BMI and BSA on survival were controversial and no predictive value of $\mathrm{BW}$ on the efficacy of EGFR-TKI was found. In addition, BMI, BSA, and BW at diagnosis are static factors and only could represent the weight condition at the time of diagnosis. Nevertheless, weight loss at presentation as a dynamic factor may be better in aspect of reflecting the change of body weight in a period. Thus, the reproducible of using weight loss at presentation as predictor may be superior to the other three weight-related clinical characteristics.
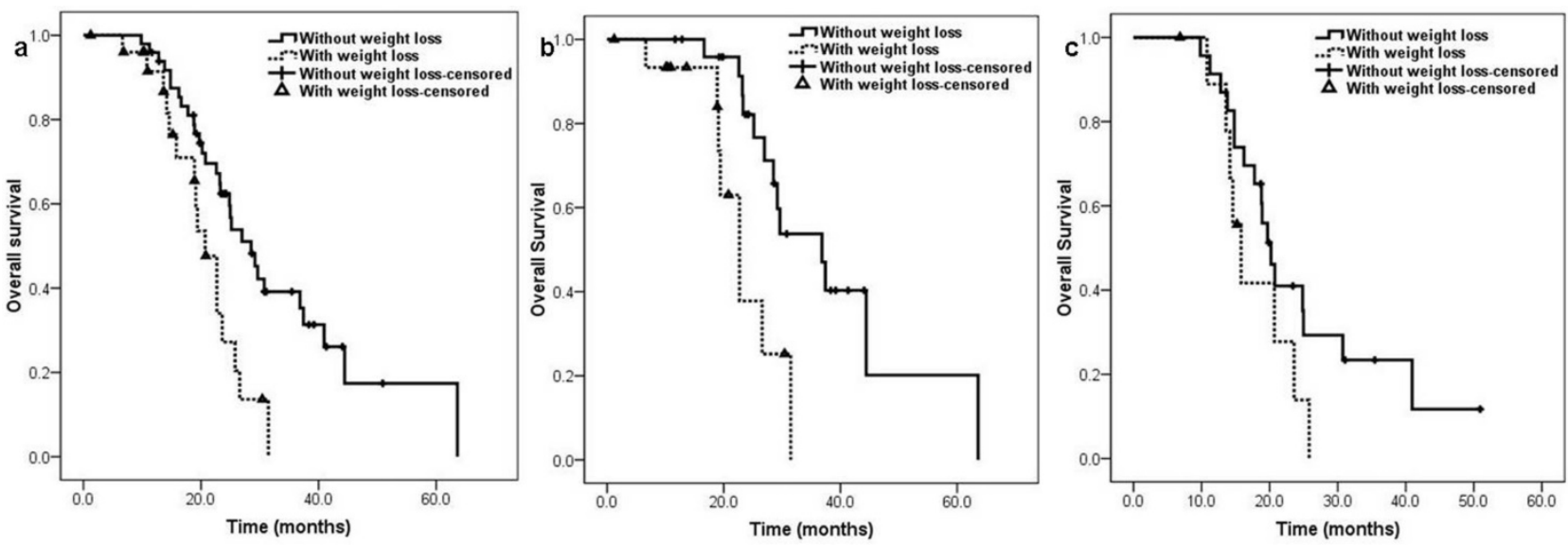

Figure 2. Kaplan-Meier curve for overall survival according to patients' weight loss status at presentation: a. overall population, b. EGFR exon 19 deletion population, c. EGFR exon 21 L858R mutation population. 
Table 5. Second-line treatment

\begin{tabular}{lll}
\hline Second-line treatment & $\begin{array}{l}\text { Without weight loss group } \\
(\mathrm{n}=49)(\%)\end{array}$ & $\begin{array}{l}\text { With weight loss group } \\
(\mathrm{n}=26)(\%)\end{array}$ \\
\hline None & $17(34.7)$ & $8(30.8)$ \\
Pemetrexed-Platinum & $8(16.3)$ & $4(15.4)$ \\
AZD9291 & $1(2.0)$ & $1(3.8)$ \\
Docetaxel-Platinum & $6(12.2)$ & $2(7.7)$ \\
Gemcitabine-Platinum & $12(24.5)$ & $7(26.9)$ \\
Paclitaxel-Platinum & $0(0.0)$ & $2(7.7)$ \\
Afatinib & $2(4.1)$ & $0(0.0)$ \\
Icotinib & $1(2.0)$ & $0(0.0)$ \\
Erlotinib & $2(4.1)$ & $1(3.8)$ \\
Sorafinib & $0(0.0)$ & $1(3.8)$
\end{tabular}

Table 6. Drug-related Toxicities

\begin{tabular}{|c|c|c|c|c|}
\hline \multirow[t]{2}{*}{ Drug-related toxicities } & \multicolumn{2}{|c|}{$\begin{array}{l}\text { Without weight loss group } \\
(\mathrm{n}=49)(\%)\end{array}$} & \multicolumn{2}{|c|}{$\begin{array}{l}\text { With weight loss group } \\
(\mathrm{n}=26)(\%)\end{array}$} \\
\hline & All grades & $\geq$ Grades 3 & All grades & $\geq$ Grades 3 \\
\hline \multicolumn{5}{|l|}{$\begin{array}{l}\text { Haematological } \\
\text { toxicities }\end{array}$} \\
\hline Leukopenia & $4(8.2)$ & $0(0.0)$ & $2(7.7)$ & $0(0.0)$ \\
\hline Neutropenia & $3(6.1)$ & $0(0.0)$ & $2(7.7)$ & $0(0.0)$ \\
\hline Thrombocytopenia & $0(0.0)$ & $0(0.0)$ & $1(2.1)$ & $0(0.0)$ \\
\hline Anaemia & $3(6.1)$ & $0(0.0)$ & $4(15.4)$ & $0(0.0)$ \\
\hline \multicolumn{5}{|l|}{$\begin{array}{l}\text { Non-haematological } \\
\text { toxicities }\end{array}$} \\
\hline $\begin{array}{l}\text { Interstitial lung } \\
\text { disease }\end{array}$ & $0(0.0)$ & $0(0.0)$ & $0(0.0)$ & $0(0.0)$ \\
\hline $\begin{array}{l}\text { Alanine } \\
\text { aminotransferase }\end{array}$ & $4(8.2)$ & $0(0.0)$ & $2(7.7)$ & $0(0.0)$ \\
\hline $\begin{array}{l}\text { Aspartate } \\
\text { aminotransferase }\end{array}$ & $2(4.1)$ & $0(0.0)$ & $1(3.8)$ & $0(0.0)$ \\
\hline Fatigue & $7(14.3)$ & $0(0.0)$ & $5(19.2)$ & $1(3.8)$ \\
\hline Diarrhea & $12(24.5)$ & $0(0.0)$ & $7(26.9)$ & $0(0.0)$ \\
\hline Rash & $18(36.7)$ & $6(12.2)$ & $10(38.5)$ & $4(15.4)$ \\
\hline Anorexia & $3(6.1)$ & $0(0.0)$ & $2(7.7)$ & $0(0.0)$ \\
\hline
\end{tabular}

Previous conclusions that weight loss was associated with worse prognosis were mostly derived from NSCLC patients received chemotherapy or concurrent chemo-radiotherapy $[2,22,23]$. It is unclearly why weight loss has a detrimental impact on survival for these advanced NSCLC. There has an explanation that weight loss is associated with reduced treatment tolerance, more treatment delays, fewer symptomatic responses, and delivery of fewer cycles of chemotherapy [12]. However, the response rate, toxicities, and the proportion of patients receiving second-line treatment were similar between two groups in our study. This indicates the mechanism that the detrimental impact of weight loss at presentation on survival in EGFR-TKI sensitive mutation NSCLC patients treated with first-line EGFR-TKI maybe differs from its impact on other types NSCLC patients. As we know, patients with weight loss often represent the presence of cachexia. In these patients, levels of numerous pro-inflammatory cytokines such as interleukin-6 (IL-6) are often increased, which affects treatment efficacies [24, 25]. On the other hand, IL-6 and EGF share signal transducers and activators of transcription 3 (STAT3) for their signaling pathways. Activated IL-6 would up-regulate STAT3 pathway, which promote tumor proliferation, metastatic and result in immunosuppression and EGFR-TKI resistance [26-28]. It is speculated that these may be the mechanisms for the shorter PFS and OS of patients with weight loss at presentation in our study.

Weight loss is usually accompanied by some alternations of physiological functions, such as immune response, cardiopulmonary status, and physical condition. Our results showed that patients with weight loss at presentation had a worse PS, whereas weight loss but not PS is predictive factor for PFS and OS in multivariate analysis. This result was similar with that of Choi and colleagues', which also found PS was not a predictive factor of PFS and OS in patients receiving first-line gefitinib treatment in multivariate analysis [29]. We speculated there were mainly two reasons. Firstly, maybe the sample size is too small to detect the difference. Secondly, EGFR-TKI could rapidly shrink the tumor and improve symptoms for EGFR-TKI sensitive mutant NSCLC patients with minimal toxicity. Therefore, patients' PS could be rapidly improved to receive more treatments to increase survival. In other words, even if the patient's PS is poor, EGFR-TKI can also improve the prognosis of the patient as long as patient has EGFR-TKI sensitive mutation.

However, there are several limitations in this study. Firstly, this is only a small sample size retrospective study in a single center and selection bias may be exist, which means the results are speculative rather than definitive. Secondly, since the definitions of weight loss are inconsistent in different studies and the time of starting weight loss is also difficult to estimate, it is hard to determine the exact cutoff value of weight loss, therefore, recall bias of patients is possible in present study. Lastly, it is well known that PS was considered to be an independent prognostic factor for survival in NSLCL; however, the PS was not balanced in the two groups, the disproportion may cause bias and exaggerate the adverse effects of weight loss on survival.

\section{Conclusions}

In summary, weight loss at presentation was associated with worse PFS and OS in EGFR-TKI sensitive mutant NSCLC patients treated with first-line EGFR-TKI. It should be considered as an important factor in the treatment decision or designing of EGFR-TKI clinical trials in NSCLC patients with EGFR-TKI sensitive mutations. However, since sample size in our study is limited, it is necessary to enlarge population to validate the impact of weight loss at presentation on survival in 
EGFR-TKI sensitive mutant NSCLC patients treated with first-line EGFR-TKI in further study.

\section{Acknowledgement}

This work was supported by Medical Science and Technology Research Foundation of Guangdong Province (Grant No. A2016307).

\section{Competing Interests}

The authors have declared that no competing interest exists.

\section{References}

1. Siegel RL, Miller KD, Jemal A. Cancer statistics, 2016. CA Cancer J Clin. 2016; 66: 7-30.

2. Mountain CF. Revisions in the International System for Staging Lung Cancer. Chest. 1997; 111 (6): 1710-7.

3. Schiller JH, Harrington D, Belani CP, et al. Comparison of four chemotherapy regimens for advanced non-small-cell lung cancer. N Engl J Med. 2002; 346: 92-98.

4. Lynch TJ, Bell DW, Sordella R, et al. Activating mutations in the epidermal growth factor receptor underlying responsiveness of non-small-cell lung cancer to gefitinib. N Engl J Med. 2004; 350: 2129-2139.

5. Mok TS, Wu YL, Thongprasert S, et al. Gefitinib or carboplatin-paclitaxel in pulmonary adenocarcinoma. N Engl J Med. 2009; 361: 947-57.

6. Lee CK, Davies L, Wu YL, et al. Gefitinib or Erlotinib vs Chemotherapy for EGFR Mutation-Positive Lung Cancer: Individual Patient Data Meta-Analysis of Overall Survival. J Natl Cancer Inst. 2017; 109(6). doi: 10.1093/jnci/djw279.

7. Maheswaran S, Sequist LV, Nagrath S, et al. Detection of mutations in EGFR in circulating lung-cancer cells. N Engl J Med. 2008; 359: 366-77.

8. Yu HA, Arcila ME, Rekhtman N, et al. Analysis of tumor specimens at the time of acquired resistance to EGFR-TKI therapy in 155 patients with EGFR-mutant lung cancers. Clin Cancer Res. 2013; 19: 2240-7.

9. Tan BH, Fearon KC. Cachexia: prevalence and impact in medicine. Curr Opin Clin Nutr Metab Care. 2008; 11: 400-407.

10. Prado CM, Lieffers JR, McCargar LJ, et al. Prevalence and clinical implications of sarcopenic obesity in patients with solid tumours of the respiratory and gastrointestinal tracts: a population-based study. Lancet Oncol. 2008; 9: 629-635.

11. Moumtzi D, Lampaki S, Zarogoulidis P, et al. Prognostic factors for long term survival in patients with advanced non-small cell lung cancer. Ann Transl Med. 2016; 4:161.

12. Ross PJ, Ashley S, Norton A, et al. Do patients with weight loss have a worse outcome when undergoing chemotherapy for lung cancers? Br J Cancer. 2004; 90: 1905-11.

13. Fearon K, Strasser F, Anker SD, et al. Definition and classification of cancer cachexia: an international consensus. Lancet Oncol. 2011; 12: 489-95.

14. Lin L, Zhao J, Hu J, et al. Comparison of the efficacy and tolerability of gefitinib with pemetrexed maintenance after first-line platinum-based doublet chemotherapy in advanced lung adenocarcinoma: single-center experience. Onco Targets Ther. 2016; 9: 6305-6314.

15. Eisenhauer EA, Therasse P, Bogaerts J, et al. New response evaluation criteria in solid tumours: revised RECIST guideline (version 1.1). Eur J Cancer. 2009; 45(2): 228-47.

16. Morio K, Minami T, Sozu T, et al. Weight Loss Associated with Platinum-Based Chemotherapy in Patients with Advanced Lung Cancer. Chemotherapy. 2016; 61:256-61.

17. Rozensztajn N, Ruppert AM, Lavole A, et al. Factors associated with early progression of non-small-cell lung cancer treated by epidermal growth factor receptor tyrosine-kinase inhibitors. Cancer Med. 2014; 3: 61-9.

18. Ichihara E, Hotta $\mathrm{K}$, Takigawa N, et al. Impact of physical size on gefitinib efficacy in patients with non-small cell lung cancer harboring EGFR mutations. Lung Cancer. 2013; 81: 435-9.

19. Kudo K, Hotta K, Ichihara E, et al. Impact of body surface area on survival in EGFR-mutant non-small cell lung cancer patients treated with gefitinib monotherapy: observational study of the Okayama Lung Cancer Study Group 0703. Cancer Chemother Pharmacol. 2015; 76: 251-6.

20. Sun H, Sun X, Zhai X, et al. Body mass index and exon 19 mutation as factors predicting the therapeutic efficacy of gefitinib in patients with epidermal growth factor receptor mutation-positive non-small cell lung cancer. Thorac Cancer. 2016; 7: 61-5

21. Imai H, Kuwako T, Kaira K, et al. Evaluation of gefitinib efficacy according to body mass index, body surface area, and body weight in patients with EGFR-mutated advanced non-small cell lung cancer. Cancer Chemother Pharmacol. 2017; 79: 497-505.
22. Crvenkova S, Pesevska M. Important prognostic factors for the long-term survival in non-small cell lung cancer patients treated with combination of chemotherapy and conformal radiotherapy. J BUON. 2015; 20: 775-81.

23. Sanders KJ, Hendriks LE, Troost EG, et al. Early Weight Loss during Chemoradiotherapy Has a Detrimental Impact on Outcome in NSCLC. J Thorac Oncol. 2016; 11: 873-9.

24. Tanaka T, Narazaki M, Masuda K, et al. Regulation of IL-6 in Immunity and Diseases. Adv Exp Med Biol. 2016; 941: 79-88.

25. Diakos CI, Charles KA, McMillan DC, et al. Cancer-related inflammation and treatment effectiveness. Lancet Oncol. 2014; 15: e493-503.

26. Zimmers TA, Fishel ML, Bonetto A. STAT3 in the systemic inflammation of cancer cachexia. Semin Cell Dev Biol. 2016; 54: 28-41.

27. Makino Y, Yoon JH, Bae E, et al. Repression of Smad3 by Stat 3 and c-Ski/SnoN induces gefitinib resistance in lung adenocarcinoma. Biochem Biophys Res Commun. 2017; 484: 269-277.

28. Yu H, Lee H, Herrmann A, et al. Revisiting STAT3 signalling in cancer: new and unexpected biological functions. Nat Rev Cancer. 2014; 14: 736-46.

29. Choi Y W, Jeon S Y, Jeong G S, et al. EGFR Exon 19 Deletion is Associated With Favorable Overall Survival After First-line Gefitinib Therapy in Advanced Non-Small Cell Lung Cancer Patients. Am J Clin Oncol. 2016; 1. 